\title{
The DEAD-box RNA helicase-like Utp25 is an SSU processome component
}

\author{
J. MICHAEL CHARETTE ${ }^{1,2}$ and SUSAN J. BASERGA ${ }^{1,2,3}$ \\ ${ }^{1}$ Department of Molecular Biophysics \& Biochemistry, Yale University School of Medicine, New Haven, Connecticut 06520, USA \\ ${ }^{2}$ Department of Therapeutic Radiology, Yale University School of Medicine, New Haven, Connecticut 06520, USA \\ ${ }^{3}$ Department of Genetics, Yale University School of Medicine, New Haven, Connecticut 06520, USA
}

\begin{abstract}
The SSU processome is a large ribonucleoprotein complex consisting of the U3 snoRNA and at least 43 proteins. A database search, initiated in an effort to discover additional SSU processome components, identified the uncharacterized, conserved and essential yeast nucleolar protein YIL091C/UTP25 as one such candidate. The C-terminal DUF1253 motif, a domain of unknown function, displays limited sequence similarity to DEAD-box RNA helicases. In the absence of the conserved DEAD-box sequence, motif la is the only clearly identifiable helicase element. Since the yeast homolog is nucleolar and interacts with components of the SSU processome, we examined its role in pre-rRNA processing. Genetic depletion of Utp25 resulted in slowed growth. Northern analysis of pre-rRNA revealed an $18 \mathrm{~S}$ rRNA maturation defect at sites $A_{0}$, $A_{1}$, and $A_{2}$. Coimmunoprecipitation confirmed association with U3 snoRNA and with Mpp10, and with components of the t-Utp/UtpA, UtpB, and U3 snoRNP subcomplexes. Mutation of the conserved motif la residues resulted in no discernable temperaturesensitive or cold-sensitive growth defects, implying that this motif is dispensable for Utp25 function. A yeast two-hybrid screen of Utp25 against other SSU processome components revealed several interacting proteins, including Mpp10, Utp3, and Utp21, thereby identifying the first interactions among the different subcomplexes of the SSU processome. Furthermore, the DUF1253 domain is required and sufficient for the interaction of Utp25 with Utp3. Thus, Utp25 is a novel SSU processome component that, along with Utp3, forms the first identified interactions among the different SSU processome subcomplexes.
\end{abstract}

Keywords: Utp25; SSU processome; DEAD-box RNA helicase; U3 snoRNA; ribosomal SSU; ribosome

\section{INTRODUCTION}

Ribosomes, the cellular machines that translate mRNA into protein, are very large ribonucleoprotein complexes consisting of four different rRNA species and approximately 80 ribosomal proteins. In eukaryotes, approximately 400 different protein and RNA/protein complexes are required for the assembly of each mature ribosome. These factors act together in a complex, highly coordinated, and poorly understood series of events that includes the endo- and exonucleolytic cleavage, folding, and chemical modification of the pre-rRNA along with its assembly with ribosomal proteins into mature ribosomes.

Ribosome biogenesis occurs in the nucleolus beginning with the transcription of the rDNA by RNA polymerase I. The resulting primary transcript, termed the " $35 \mathrm{~S}$ pre-

Reprint requests to: Susan J. Baserga, Department of Molecular Biophysics \& Biochemistry, Yale University School of Medicine, New Haven, CT 06520, USA; e-mail: susan.baserga@yale.edu; fax: (203) 7856309.

Article published online ahead of print. Article and publication date are at http://www.rnajournal.org/cgi/doi/10.1261/rna.2359810.
rRNA," is a long polycistronic molecule that encodes three of the four rRNAs that form the small (18S rRNA; SSU) and large (5.8S and 25/28S rRNA; LSU) subunits of the mature ribosome (the $5 \mathrm{~S}$ rRNA, a LSU component, is encoded by a separate transcription unit). The pre-rRNA also contains several noncoding external and internal transcribed spacer (ETS and ITS) sequences that are excised during pre-rRNA processing (Fig. 1).

In the biogenesis of the ribosomal SSU, the $18 \mathrm{~S}$ rRNA is liberated from the $35 \mathrm{~S}$ pre-rRNA through a series of endonucleolytic cleavage events. These occur in the $5^{\prime}$-ETS at sites $\mathrm{A}_{0}$ and $\mathrm{A}_{1}$ (defines the mature $5^{\prime}$-end of the $18 \mathrm{~S}$ ) and in ITS1 at the $\mathrm{A}_{2}$ site. The resulting $18 \mathrm{~S}$ precursor, termed the "20S," is then exported to the cytoplasm for cleavage at site $\mathrm{D}$ (defines the mature 3 ' -end of the molecule), while the remaining pre-LSU transcript, called the " $27 \mathrm{SA}_{2} / 27 \mathrm{SA}_{3}$," is further processed into the mature $5.8 \mathrm{~S}$ and $25 / 28 \mathrm{~S}$ rRNAs of the LSU of the ribosome (Henras et al. 2008; Strunk and Karbstein 2009).

A very large ribonucleoprotein complex, termed the "SSU processome" (Dragon et al. 2002; Bernstein et al. 2004), mediates cleavage events in the $35 \mathrm{~S}$ pre-rRNA at 


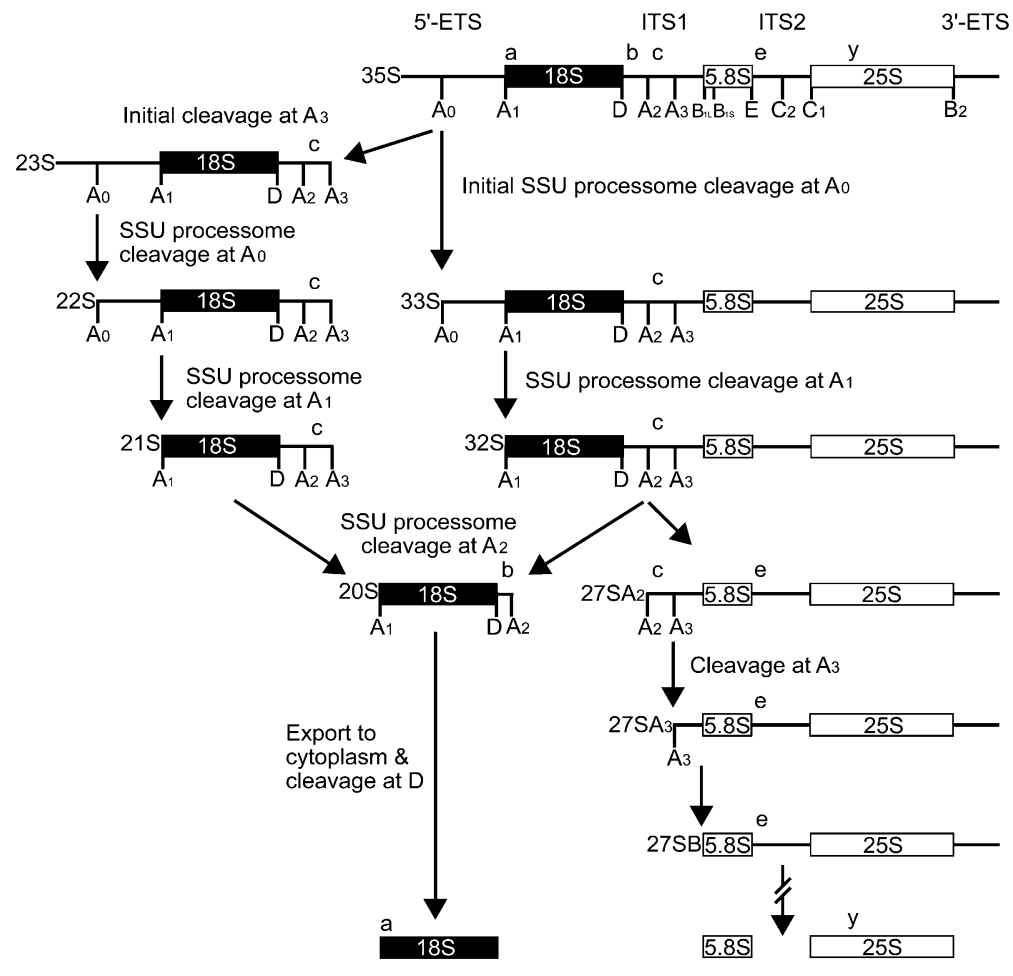

FIGURE 1. The pre-rRNA processing pathway in yeast. Cleavage at sites $\mathrm{A}$ to $\mathrm{E}$ (indicated in uppercase letters under the pre-rRNA schematic) releases the mature $18 \mathrm{~S}, 5.8 \mathrm{~S}$, and $25 \mathrm{~S}$ rRNAs from the $35 \mathrm{~S}$ pre-rRNA transcript. The SSU processome guides cleavage at sites $\mathrm{A}_{0}$ (in the $5^{\prime}$-ETS), $A_{1}$ (mature $5^{\prime}$-end of the $18 \mathrm{~S}$ ), and $\mathrm{A}_{2}$ (in ITS1), thereby liberating the $18 \mathrm{~S}$ rRNA from the $35 \mathrm{~S}$ pre-rRNA. The $23 \mathrm{~S}$ pre-rRNA is produced by an alternative processing pathway through an initial cleavage of the $35 \mathrm{~S}$ pre-rRNA at site $\mathrm{A}_{3}$. The lowercase letters above the rRNA schematic denote the oligonucleotide hybridization probes used in Figure 3B.

sites $A_{0}, A_{1}$, and $A_{2}$. This 2.2-MDa complex, of similar size to the ribosome (Dragon et al. 2002), consists of the U3 small nucleolar RNA (snoRNA) and at least 43 proteins. It can be visualized as the terminal knobs observed on the 5 '-ends of growing pre-rRNA "Christmas trees" (Dragon et al. 2002; Osheim et al. 2004). Through base-pairing interactions with the (pre-) rRNA, the U3 snoRNA, by a complex and poorly understood mechanism, guides the multiple sequence-specific pre-rRNA cleavage events that eventually liberate the mature $5^{\prime}$-end of the $18 \mathrm{~S}$ rRNA (Beltrame and Tollervey 1995; Hughes 1996; Méreau et al. 1997; Sharma and Tollervey 1999). In genetic studies of the SSU processome, depletion of the U3 snoRNA or of any of its 41 essential protein constituents results in the loss of cleavage at sites $A_{0}, A_{1}$, and $A_{2}$ but not at site $A_{3}$ (Hughes 1996; Dunbar et al. 1997; Lee and Baserga 1999; Sharma and Tollervey 1999; Dragon et al. 2002; Bernstein et al. 2004; Bleichert et al. 2006). This is seen as a loss of the $20 \mathrm{~S}$ and $18 \mathrm{~S}$ rRNAs and an accumulation of unprocessed $35 \mathrm{~S}$ and $23 \mathrm{~S}$ pre-rRNAs (generated through an initial cleavage of the $35 \mathrm{~S}$ pre-rRNA at site $\mathrm{A}_{3}$ ). Maturation of the $27 \mathrm{SA}_{2} /$ $27 \mathrm{SA}_{3}$ into the $5.8 \mathrm{~S}$ and $25 / 28 \mathrm{~S}$ rRNA remains unaffected (Fig. 1). By virtue of its multiple base-pairing interactions with the pre-rRNA, U3 snoRNA has also been postulated to exert a chaperone-like activity in the cotranscriptional folding and structural rearrangements necessary to the proper folding of the 18S rRNA and assembly with ribosomal proteins into the mature SSU of the ribosome (Venema and Tollervey 1999; Dragon et al. 2002).

Very little is known about the overall assembly and architecture of the SSU processome. Some of its component proteins are known to associate into preformed subcomplexes, namely, the transcriptional Utps ( $\mathrm{t}-\mathrm{Utps}$ or UtpA subcomplex: t-Utp4, 5, 8, 9, 10, 15, 17, and Pol5) that link pre-rRNA transcription to processing (Gallagher et al. 2004; Krogan et al. 2004; Granneman and Baserga 2005), the UtpB subcomplex (Utp1, 6, 12, 13, 18, and 21) (Krogan et al. 2004; Champion et al. 2008), and the UtpC subcomplex (Utp22, Rrp7, and the four subunits of casein kinase II) (Krogan et al. 2004). We have previously used the yeast two-hybrid methodology to map the protein-protein interactions within the UtpB subcomplex (Champion et al. 2008), giving some insight into how the subcomplex is assembled from its individual components. Similarly, we have also shown that Mpp10 associates with Imp3 and Imp4 (Lee and Baserga 1999). Protein-protein interaction maps of the UtpA subcomplex are also available (Tarassov et al. 2008; Freed and Baserga 2010). Importantly, the protein-protein interactions linking the UtpA, UtpB, UtpC, and Mpp10 subcomplexes remain unknown.

RNA helicases factor prominently in ribosome biogenesis, with 10 known RNA helicases participating in SSU assembly (Granneman et al. 2006a; Bleichert and Baserga 2007). Presumably, RNA helicases mediate the many dynamic pre-rRNA folding, RNA structural rearrangement, and RNA/protein remodeling events that occur during ribosome biogenesis. Most of these are members of the DEAD-box or DEAH-box families of RNA helicases, an eponymous name for a conserved D-E-A-D sequence, the ATPase domain of motif II/Walker B. They possess nine conserved motifs (Fig. 2; Rocak and Linder 2004; Cordin et al. 2006). Motif I (Walker A), motif II (Walker B/DEAD), and motifs III and VI are involved in various aspects of NTP binding, hydrolysis, and coupling of NTP hydrolysis with helicase activity. Motifs Ia, Ib, IV, and V participate in substrate binding. Motif $\mathrm{Q}$ is involved in both NTP binding/hydrolysis and RNA binding. The mechanism by which DEAD-box RNA helicases reach their target substrate(s) remains unclear. However, in many cases, substrate 

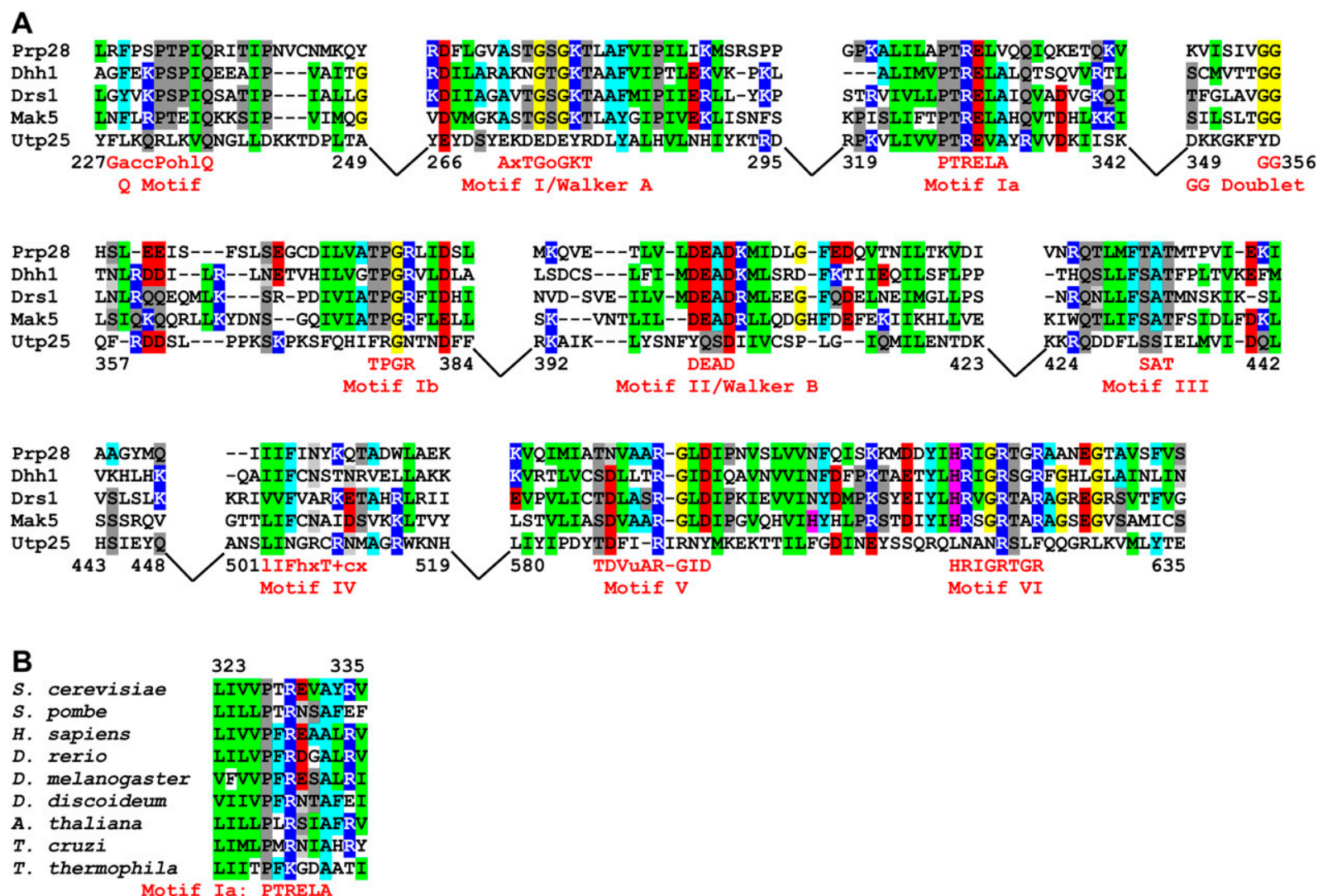

FIGURE 2. Alignment of Utp25 with other DEAD-box RNA helicases. (A) Alignment of the yeast Utp25 with known yeast DEAD-box RNA helicases. The DEAD-box RNA helicases are presented in increasing order of sequence similarity to Utp25, with Prp28 being the least similar and Mak5 being the most similar. Numbers delineate the regions of Utp25 shown in the alignment. Areas of low sequence similarity outside of the conserved sequence blocks were removed and are depicted as gaps. Motif consensus sequences are derived from Cordin et al. (2006), with uppercase letters denoting well-conserved residues and conservative substitutions depicted by lowercase letters- "a" represents a conserved aromatic amino acid (F, W, or Y), "c" a charged group (D, E, H, K, or R), "h" a hydrophobic amino acid (A, F, G, I, L, M, P, V, W, or Y), "l" an aliphatic residue (I, L, or V), "o" an alcohol (S or T), "u" is A or G, "+" a positively charged group (H, K, or R), and " $\mathrm{x}$ " any residue. (B) The sequence of motif Ia is phylogenetically conserved among all eukaryotic supergroups. The complete alignment of Utp25 homologs can be found as Supplemental Figure S1, along with the sequence accession numbers.

specificity is believed to be mediated by protein co-factors that, through protein-protein interactions, recruit the helicase to its site of activity (Granneman et al. 2006b).

Here, we present evidence that the conserved yeast open reading frame YIL091C is a previously uncharacterized ribosome biogenesis factor. We demonstrate its association with U3 snoRNA and Mpp10 and with components of the $\mathrm{t}$-Utp/UtpA, UtpB, and U3 snoRNP subcomplexes of the SSU processome. Furthermore, we show that genetic depletion of the protein product of YIL091C abrogates $18 \mathrm{~S}$ rRNA processing through the loss of cleavage at sites $A_{0}$, $A_{1}$, and $A_{2}$ in the $35 S$ pre-rRNA. While this protein displays some sequence similarity to DEAD-box RNA helicases, we show that most of the conserved helicase motifs, including the DEAD sequence, are absent. Furthermore, mutational ablation of the conserved Ia motif results in no discernable growth defects, thereby suggesting that this motif is dispensable for Utp25 function. Importantly, a yeast two-hybrid screen of YIL091C against other SSU processome compo- nents revealed a number of interacting proteins, including the first protein-protein interactions linking the different subcomplexes of the SSU processome. We also show that the helicase-like DUF1253 domain of YIL091C is required and sufficient for interaction with Utp3. Thus, we name YIL091C the "twenty-fifth U three-associated protein" (UTP25).

\section{RESULTS}

\section{A yeast database search identifies UTP25 as a putative SSU processome component}

We searched the Saccharomyces cerevisiae genome database (Issel-Tarver et al. 2002) for additional, novel components of the SSU processome. Specifically, we searched for unannotated proteins associated with the Gene Ontology (GO) terms "nucleolus" and "ribosome biogenesis" (Ashburner et al. 2000). The protein product of YIL091C (UTP25) was 
identified as one such candidate based on the following criteria: (1) it was an uncharacterized gene (Peña-Castillo and Hughes 2007); (2) it was localized in the nucleolus in yeast, zebrafish, and humans (Hazbun et al. 2003; Huh et al. 2003; Ahmad et al. 2009), the site of ribosome biosynthesis; (3) high-throughput studies proposed an association with the SSU processome components Mpp10 and Utp3 (Krogan et al. 2006); and (4) it was an essential gene product in both yeast (Giaever et al. 2002) and zebrafish (Chen et al. 2005), as are 41 out of the 43 known yeast components of the SSU processome. Furthermore, RNA helicases factor prominently in ribosome biosynthesis, and Utp25 was annotated as a putative DEAD-box RNA helicase based on sequence similarity searches (i.e., BLAST) and protein structure predictions (Hazbun et al. 2003).

\section{Utp25 is a conserved DEAD-box RNA helicase-like protein}

A search for homologs of the yeast UTP25 identified orthologs in all eukaryotic supergroups (animals and yeasts, plants and the polyphyletic protists) (Keeling et al. 2005) for which sequence information is available, suggesting that this protein was present in the common ancestor of all eukaryotes (Supplemental Fig. S1). This 721-amino-acid, $84-\mathrm{kDa}$ protein consists of two domains. The $\mathrm{N}$-terminal region (amino acids 1 to $\sim 213$ ) contains no known sequence or structural motifs and is poorly conserved. Instead, it displays regions of simple, repetitive, negatively charged sequences, such as poly-DE repeats and poly-E regions. Many other RNA metabolism and SSU processome proteins contain similar repetitive regions, including Mpp10, Rrp9/U3-55k, Utp3, Utp14, and Utp18. The C-terminal region (amino acids $\sim 214$ to 721 ) displays high sequence conservation and contains the domain of unknown function, DUF1253. This domain, only found in Utp25 homologs, displays limited sequence similarity to DEAD-box RNA helicases (Fig. 2).

The DUF1253 region of the yeast Utp25 was aligned with known yeast DEAD-box RNA helicases (Fig. 2A). Comparison of the aligned nonhomologous DEAD-box RNA helicases (Mak5, Drs1, Dhr1, and Prp28) revealed a low level of sequence conservation with Utp25 over the entire length of the protein, especially outside of the functional motifs. The highly conserved regions-corresponding to the helicase motifs Q, I (Walker A), Ia, Ib, II (Walker B; DEAD), III, IV, V, and VI-were clearly conserved among the helicases, but not to the same extent in Utp25. However, Utp25 frequently displayed some degree of sequence similarity flanking the conserved helicase motifs (e.g., motif I). With the exception of motif Ia and portions of motifs $\mathrm{Q}, \mathrm{IV}$, and $\mathrm{V}$, this similarity did not extend to the known helicase catalytic residues. Interestingly, of the conserved motifs, comparison of the aligned Utp25 sequences among divergent species revealed that motif Ia is phylogenetically conserved in all eukaryotes (Fig. 2B).

\section{Depletion of Utp25 leads to reduced growth}

Utp25 is encoded by an essential gene in yeast (Giaever et al. 2002). To examine the function of the uncharacterized Utp25 protein, we constructed a yeast strain that expressed a chromosomal N-terminal 3xHA-tagged UTP25 under the control of a galactose-inducible/glucose-repressible promoter (GAL::3xHA-UTP25). This strain was compared to a strain similarly constructed for genetic depletion of the essential UtpB subcomplex protein, Utp6 (GAL::3xHA-UTP6) (Dragon et al. 2002). The levels of each of the Utp25 and Utp6 proteins were undetectable by Western blotting with anti-HA antibodies after growth in glucose for $24 \mathrm{~h}$ (Fig. $3 \mathrm{~A}$, inset). Analysis of growth following genetic depletion of Utp25 and Utp6 revealed a similar decrease in the growth rate among the two proteins when compared to the parental YPH499 strain (Fig. 3A).

\section{Utp25 is required for pre-18S rRNA processing}

To examine if the growth defect observed upon Utp25 depletion is due to impaired ribosome production, we asked whether pre-rRNA processing was impaired in yeast depleted of Utp25 by Northern hybridization analysis (Fig. 3B). Genetic depletion of Utp 25 by growth for up to $24 \mathrm{~h}$ in nonpermissive glucose media revealed an $18 \mathrm{~S}$ maturation defect. This can be seen by the accumulation of unprocessed $35 \mathrm{~S}$ pre-rRNA precursor (Fig. 3B, cf. lanes 4-6 with lanes 1-3). A decrease in the abundance of the $27 \mathrm{SA}_{2}$ (Fig. $3 \mathrm{~B}$, cf. lanes 13-15 with lanes 10-12) and an increase in the level of $23 \mathrm{~S}$ (a pre-18S species generated through an initial cleavage of the $35 \mathrm{~S}$ pre-rRNA at site $\mathrm{A}_{3}$ ) (Fig. $3 \mathrm{~B}$, cf. lanes 13-15 with lanes 10-12) was also seen. Most importantly, levels of the 20S pre-rRNA (Fig. 3B, cf. lanes 13-15 with lanes 10-12) and of the mature $18 \mathrm{~S}$ rRNA (Fig. 3B, cf. lanes 22-24 with lanes 19-21) were clearly reduced. This pattern of accumulation and reduction in the levels of pre-rRNAs, also seen upon Utp6 depletion (Dragon et al. 2002), is typical of depletion of SSU processome proteins and is diagnostic of $18 \mathrm{~S}$ pre-rRNA processing defects at sites $\mathrm{A}_{0}$, $A_{1}$, and $A_{2}$. In contrast, the levels of mature $25 S$ rRNA were not significantly changed (Fig. 3B, cf. lanes 22-24 with lanes 19-21), implying that no processing defects occur for the LSU rRNAs. Taken together, these results support a direct role for Utp25 in $18 \mathrm{~S}$ rRNA processing, specifically at sites $A_{0}, A_{1}$, and $A_{2}$.

\section{Utp25 is an SSU processome component}

The SSU processome is a large ribonucleoprotein complex consisting of the U3 snoRNA and at least 43 proteins. This complex guides the endonucleolytic cleavage events at sites $A_{0}, A_{1}$, and $A_{2}$ that liberate the mature 18S rRNA from the pre-rRNA transcript. Since we found Utp25 to be also required for pre-rRNA processing at these sites, we examined whether this uncharacterized protein represents a novel 

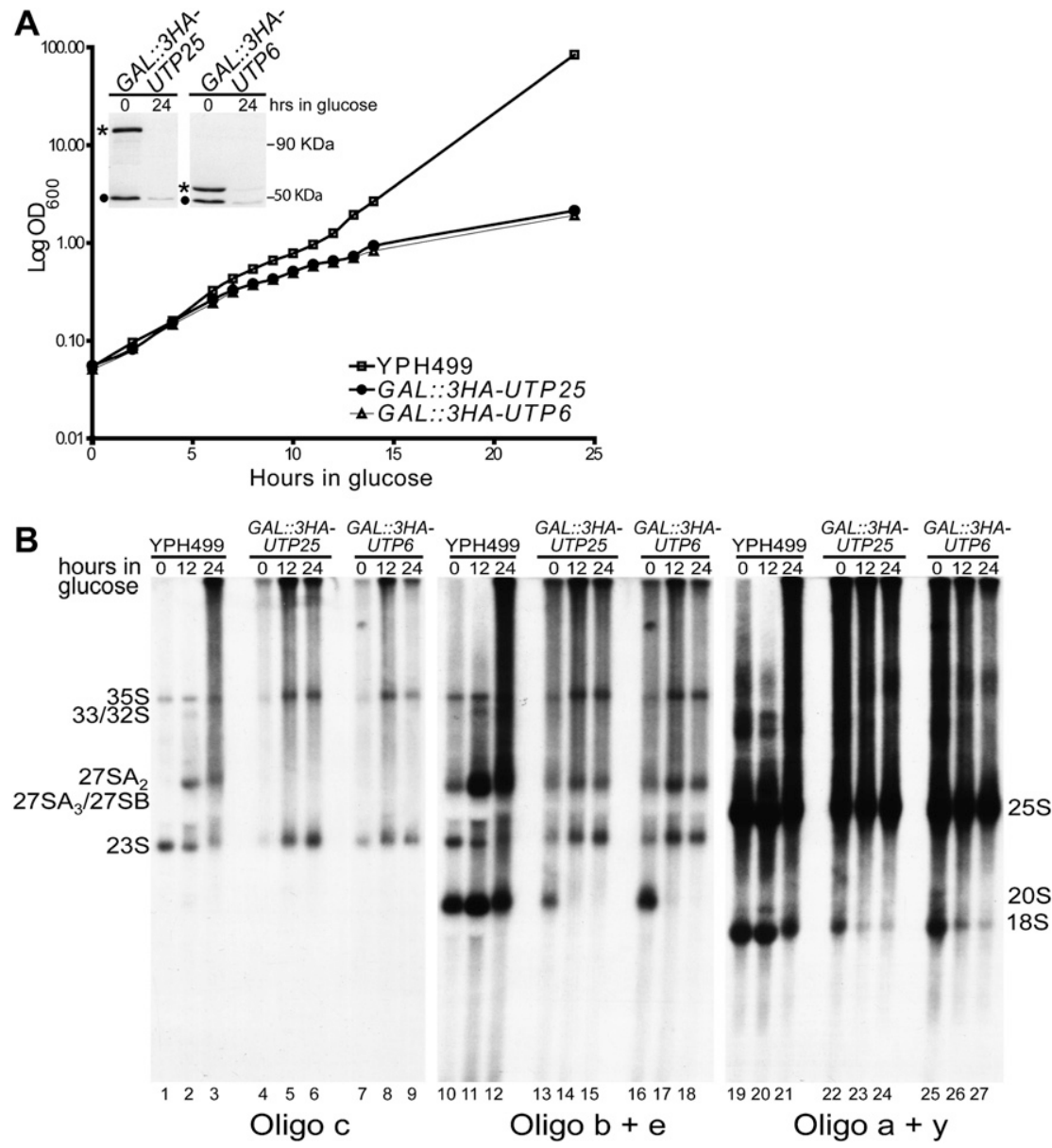

FIGURE 3. Utp 25 is required for growth and for $18 \mathrm{~S}$ pre-rRNA processing. (A) Genetic depletion of Utp25 after $24 \mathrm{~h}$ of growth in nonpermissive glucose medium impairs cell growth. (Inset) Utp25 and Utp6 (Dragon et al. 2002) levels $\left(^{*}\right.$ ) are reduced after genetic depletion for $24 \mathrm{~h}$. Total yeast extract, separated on the same SDS-PAGE gel, was analyzed by Western blotting with an anti-HA antibody. A $50-\mathrm{kDa}$ nonspecific cross-reacting band is also seen $(\bullet)$. (B) Genetic depletion of Utp25 reveals an 18S rRNA maturation defect. The parental strain YPH499 along with GAL::3HA-UTP6 (Dragon et al. 2002) are shown as controls. Oligonucleotide hybridization probes $\mathrm{c}, \mathrm{b}+\mathrm{e}$, and $\mathrm{a}+\mathrm{y}$ are depicted in Figure 1 as lowercase letters above the rRNA schematic.

component of the SSU processome. Immunoprecipitation experiments using a 3xHA-tagged Utp25 as bait resulted in weak but consistent coimmunoprecipitation of Mpp10 (Fig. 4A, lane 5), a known SSU processome-specific protein component, and of the U3 snoRNA (Fig. 4B, lane 6). Similarly, both Mpp10 and the U3 snoRNA are coimmunoprecipitated with 3xHA-tagged Utp6 and Utp21, both known SSU processome components (Fig. 4A,B; Dragon et al. 2002; Bernstein et al. 2004). The low immunoprecipitation efficiency of Utp25 in comparison to Utp6 and Utp21 is reproducibly observed and may result from a transient or weak association of this protein with the SSU processome, a phenomenon that has been seen with other SSU processome components (Bleichert et al. 2006). The ability of Utp25 to immunoprecipitate known protein and RNA components of the SSU processome argues that this protein is a novel member of this large pre-rRNA processing complex.

We then asked whether Utp25 is associated with other representative components of the SSU processome. For that, we used GAL::3xHA-UTP25 strains carrying C-terminal TAP-tag fusions of t-Utp8, Utp18, or Rrp9, members of the $\mathrm{t}$-Utp/UtpA, UtpB, and U3 snoRNP subcomplexes. Immunoprecipitation studies using 3xHA-tagged Utp25 as bait resulted in the coimmunoprecipitation of Mpp10 along with t-Utp8, Utp18, and Rrp9 (Fig. 4C). Thus, the ability of Utp25 to immunoprecipitate members of the $\mathrm{t}-\mathrm{Utp} / \mathrm{UtpA}, \mathrm{UtpB}, \mathrm{Mpp} 10$, and U3 snoRNP subcomplexes argues that this protein is associated with the assembled SSU processome particle.

\section{The highly conserved residues of motif la, implicated in substrate RNA binding, are not required for Utp25 function}

Yeast Utp25 has been classified as a DEAD-box RNA helicase by virtue of its highly conserved motif Ia, despite the absence of the other conserved helicase motifs (Hazbun et al. 2003). Motif Ia, with a consensus sequence of "PTRELA," is known to function in substrate RNA binding (Rocak and Linder 2004; Cordin et al. 2006). It is clearly represented in the yeast Utp25 by the "PTREVA" residues (Fig. 2A) and is furthermore conserved in homologs of Utp25 from disparate parts of the eukaryotic tree (Fig. 2B). We tested whether these conserved residues within motif Ia are essential for Utp25 protein function in vivo, as would be expected if this protein were a bona fide DEAD-box RNA helicase. For that, we mutated the conserved motif Ia sequence of Utp25, PTREVA, by replacing all the amino acids with alanines, "AAAAAA" (Fig. 5A). Such a mutation would be expected to abolish motif Ia while minimizing disturbances to the overall structure of the protein. Wild-type and motif Ia mutant Utp25 were cloned into p415-GPD, a low-copy yeast expression vector with a constitutive GPD promoter (Mumberg et al. 1995), and transformed into the GAL::3xHA-UTP25 strain (Fig. 5B). We then tested whether expression of the plasmid-encoded wild-type and motif Ia mutant Utp25 could rescue, by complementation, the growth defect of cells depleted of endogenous Utp25 (Fig. 5C). As expected, plasmid-derived wild-type Utp25 was able to complement 
A

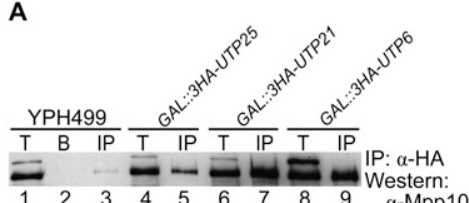

B
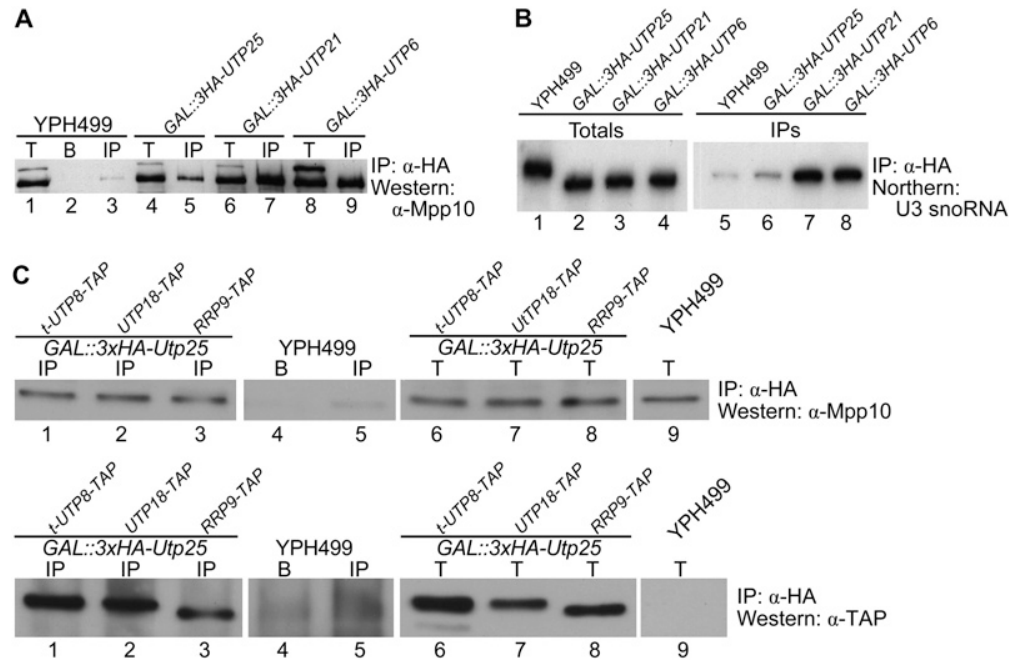

FIGURE 4. Utp25 is an SSU processome component. The 3xHA-tagged Utp25 coimmunoprecipitates Mpp10 $(A)$ and the U3 snoRNA $(B)$, both known protein and RNA components of the SSU processome. Anti-HA antibodies were used to immunoprecipitate 3xHA-tagged Utp25, and Utp6 and Utp21, both known SSU processome components (Dragon et al. 2002; Bernstein et al. 2004), and the untagged parental strain YPH499. For the Western analysis, total input ( $\mathrm{T} ; 5 \%)$, mock IP with uncoupled beads $(B)$, and the immunoprecipitates (IP) were separated by SDS-PAGE and blotted with an anti-Mpp10 antibody. For the Northern analysis, RNA was extracted from the total input (10\%) and the IPs (as per the Western analysis), resolved on a denaturing gel and hybridized with a probe complementary to the U3 snoRNA. (C) Utp25 coimmunoprecipitates t-Utp8, Utp18, and Rrp9, members of the t-Utp/UtpA, UtpB, and U3 snoRNP subcomplexes. The immunoprecipitations with anti-HA antibodies and Western analysis with anti-Mpp10 antibody were done as described above. The membrane was subsequently stripped and re-probed with anti-TAP antibody. an "arginine finger," within the degenerate motif VI sequence of Utp25. In DEAD-box RNA helicases, motif VI contains three arginine residues, the first and third being absent from Utp25. We therefore investigated the role of the putative "arginine finger" of Utp25 by mutation of the arginine to alanine. Using the system described above for mutation of motif Ia, we tested whether expression of the plasmid-encoded wildtype and "arginine finger" mutant Utp25 could rescue the growth defect of cells depleted of endogenous Utp25 (Supplemental Fig. S2). We found that plasmidderived Utp25 with an "arginine finger"to-alanine mutation was able to rescue the growth defects of Utp25-depleted cells at $30^{\circ} \mathrm{C}, 17^{\circ} \mathrm{C}$, and $35^{\circ} \mathrm{C}$. Therefore, mutation of this arginine is not detrimental to Utp25 function.

Taken together, the lack of phenotypic consequence upon mutational ablation of motif Ia and of the putative arginine finger further supports the observation that Utp25 is not a bona fide DEAD-box RNA helicase. cells depleted of endogenous Utp25. Unexpectedly, plasmid-derived Utp25 with the motif Ia-to-alanine mutation was also able to rescue the growth defect of Utp25-depleted cells at $30^{\circ} \mathrm{C}$ (Fig. 5C). Cold sensitivity is typically a hallmark of defects in RNA folding and ribonucleoprotein assembly (Guthrie et al. 1969), whereas temperature sensitivity is often diagnostic of disruptions in protein folding (Goldenberg 1988). Since growth defects were not observed at $30^{\circ} \mathrm{C}$, we assayed the utp25-motif Ia mutant for growth under both cold-sensitive $\left(17^{\circ} \mathrm{C}\right)$ and temperature-sensitive $\left(35^{\circ} \mathrm{C}\right)$ conditions (Fig. 5C). Growth defects were not observed at either temperature. We further tested this using the more sensitive liquid growth assay (Fig. 5D) and similarly found no growth defects.

Motif VI of DEAD-box RNA helicases (HRIGRTGR) is known to be important in both RNA binding and ATPase activity (Cordin et al. 2006). Furthermore, the first and second arginines of motif VI have been proposed to bind to the $\gamma$-phosphate of ATP (Caruthers et al. 2000). More specifically, the second arginine, essential for ATP-binding and hydrolysis, has been proposed to act as an "arginine finger" in transition state stabilization during ATP hydrolysis (Cordin et al. 2006; Elles and Uhlenbeck 2008).

Alignment of Utp25 with known DEAD-box RNA helicases (Fig. 2A) identified an arginine residue, possibly corresponding to the second arginine that is proposed to act as

\section{Identification of the first interactions linking the SSU processome subcomplexes: Utp25 interacts with Utp3 and with the UtpB and Mpp10 subcomplexes}

Having established that Utp25 is an SSU processome component, we then sought to determine its protein-protein interacting partners. High-throughput affinity capture-mass spectrometry studies (Krogan et al. 2006) suggest that Utp25 co-complexes with Utp3 (Sas10) and Mpp10, both known components of the SSU processome (Dunbar et al. 1997; Dragon et al. 2002). We therefore wished to determine if direct, binary protein-protein interactions form the basis of the co-complex interactions of Utp25 with Utp3 and Mpp10. Furthermore, while co-complex data are available for the t-Utp/UtpA, UtpB, and UtpC subcomplexes (Krogan et al. 2004) and binary protein-protein interaction maps exist for the t-Utp/UtpA (Freed and Baserga 2010), UtpB (Champion et al. 2008), and Mpp10 (Lee and Baserga 1999) subcomplexes, the interacting partners of the majority of SSU processome proteins remain undetermined. Therefore, we used a directed yeast two-hybrid approach to map the protein-protein interactions among Utp25 and Utp3 and their potential contacts with the UtpB and Mpp10 subcomplexes.

The protein components of the UtpB and Mpp10 subcomplexes and the single proteins Utp25 and Utp3 were 

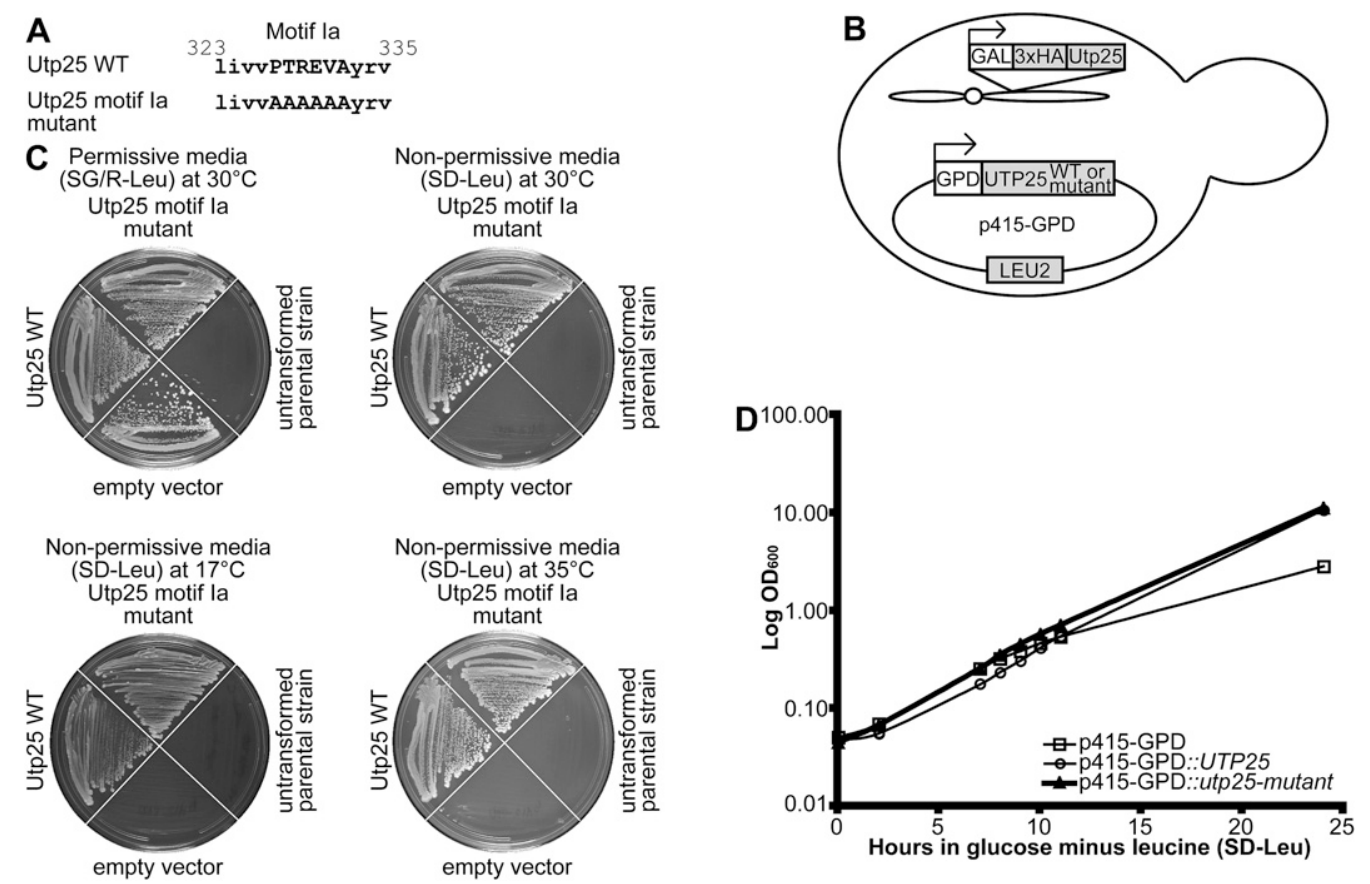

FIGURE 5. The conserved motif Ia is not required for Utp25 function. (A) Wild-type and mutant motif Ia sequences, in which the residues were all mutated to alanines, of the yeast Utp25. (B) The full-length wild-type (p415-GPD ::UTP25) and mutant (p415-GPD::utp25-motif Ia mutant) yeast UTP25 sequences were cloned into p415-GPD, a low-copy yeast expression vector with a constitutive GPD promoter, and transformed into the parental GAL::3HA-UTP25 strain. (C) Complementation by the plasmid-borne wild-type or mutant Utp25 was assayed by rescue of the growth defect after depletion of endogenous Utp25 by growth on nonpermissive media (SD-Leu) at 30, 35, and $17^{\circ} \mathrm{C}$ after $7 \mathrm{~d}$ of growth. The untransformed parental GAL::3HA-UTP25 strain, along with growth of all transformed strains on permissive medium (SG/R-Leu) enabling expression of the endogenous chromosomal Utp25, is also shown. (D) Growth curve of cells expressing no (squares), wild-type (circles), or motif Ia mutant (triangles) Utp25 proteins from the p415-GPD plasmid. Cells were grown in SG/R-Leu to exponential phase and transferred to SD-Leu. Cells were maintained in mid-log phage by frequent dilution, and growth was monitored for $24 \mathrm{~h}$ at $30^{\circ} \mathrm{C}$.

cloned into yeast two-hybrid vectors, as both bait and prey, using the yeast MORF library (Gelperin et al. 2005) and recombinatorial cloning (Hartley et al. 2000). Baits, in pAS$\mathrm{GW}$, were transformed into the yeast strain PJ69-4 $\alpha$, and preys, in pACT-GW, were transformed into the PJ69-4a strain (James et al. 1996). Yeast cells were mated in an 11-by-11 array of all pairwise combinations, and interactions between bait and prey fusion proteins were scored by growth on selective medium lacking leucine, tryptophan, and histidine and including the inhibitor 3-AT. Results with proteins not previously assayed in this way are shown in Figure 6A and tabulated in Figure 6B. Figure 6C represents all of the interactions obtained among the assayed proteins.

Our results recapitulate the previously published interaction maps of the UtpB and Mpp10 subcomplexes (shown as solid lines in Fig. 6C; Lee and Baserga 1999; Champion et al. 2008; data not shown). Furthermore, we find that Utp25 directly interacts with both Utp3 and Mpp10, thereby suggesting that direct, binary proteinprotein interactions underlie the previously published cocomplex association of these proteins (Krogan et al. 2006). More importantly, Utp25 was also found to directly in- teract with Utp21 of the UtpB subcomplex, and Utp3 was found to interact directly with Utp6 and Utp21 of the UtpB subcomplex and with Mpp10. Similarly, Utp6 was found to also interact with Mpp10, and Utp3 was found to interact with itself (novel interactions shown as arrows in Fig. 6C). Of particular interest, Utp25 and Utp3 both interact with members of the UtpB and Mpp10 subcomplexes, thereby representing the first determined protein-protein interactions linking different subcomplexes of the SSU processome.

Utp25 consists of an $\mathrm{N}$-terminal region containing no known sequence or structural motifs and a highly conserved C-terminal region consisting of the DEAD-box RNA helicase-like DUF1253 domain (Fig. 2; Supplemental Fig. S1). We therefore asked which region of Utp25 is responsible for the yeast two-hybrid interactions observed with Utp3. For that, we created C-terminal truncations of Utp25 along with an N-terminal truncation corresponding to the DEAD-box RNA helicase-like DUF1253 domain. The yeast two-hybrid screen was performed as described above in an array of all pairwise combinations. We find that the DEAD-box RNA helicase-like DUF1253 domain of Utp25 is required and sufficient for interaction with Utp3 (Fig. 7). 

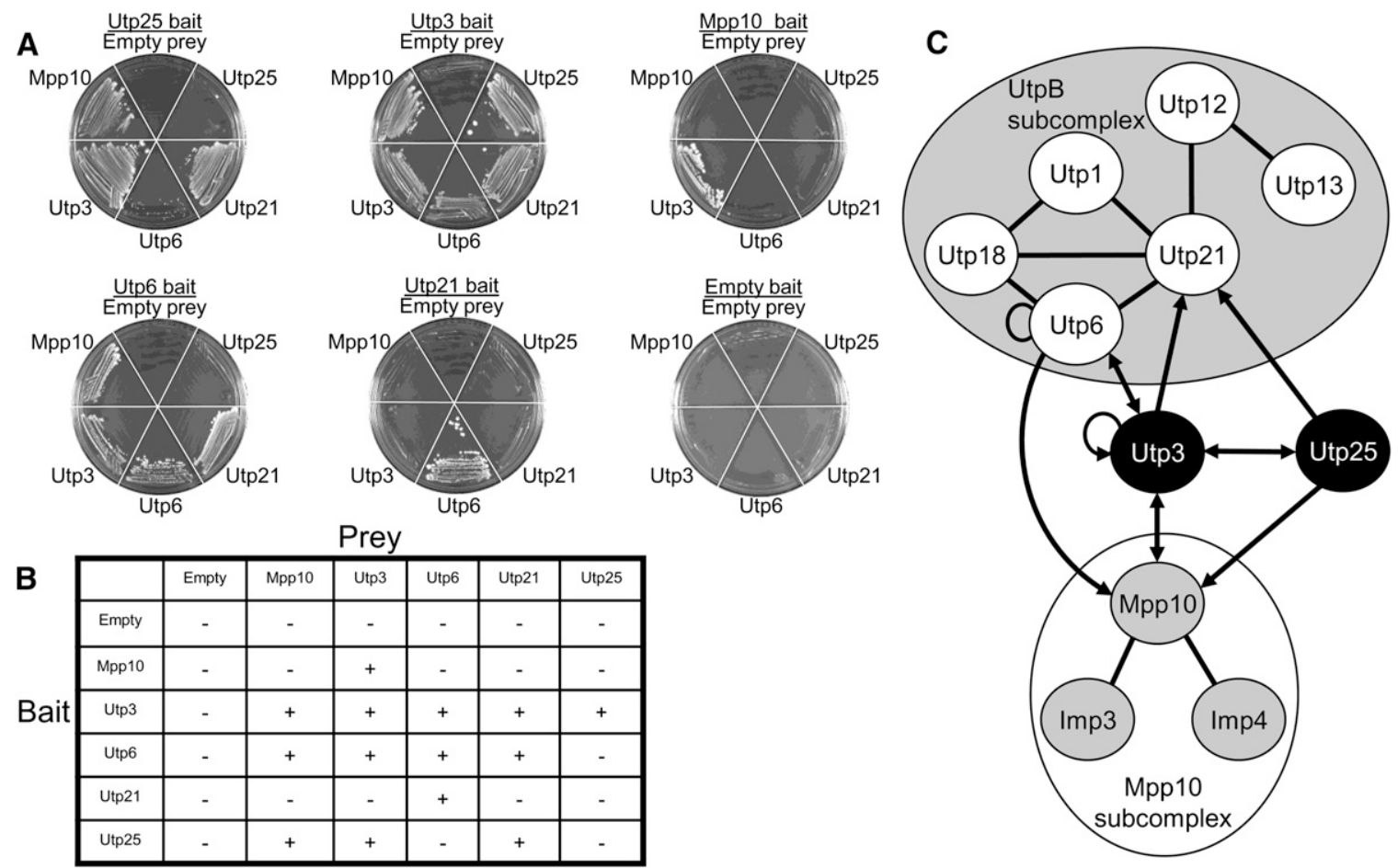

FIGURE 6. Utp25 and Utp3 link the UtpB and Mpp10 subcomplexes. (A) Re-streaks of the bait (underlined) and prey (shown surrounding the plate) protein-protein interaction screen from the $11 \times 11$ yeast two-hybrid array, focusing on previously unknown interactions involving Utp25 and Utp3. Yeast cells were assayed for growth on selective medium lacking leucine, tryptophan, and histidine and containing 3-AT. (B) Tabulation of the novel positive $(+)$ and negative $(-)$ protein-protein interactions involving Utp25 and Utp3. Previously known and recapitulated protein-protein interactions within the UtpB and Mpp10 subcomplexes are not shown. $(C)$ Diagram of the obtained proteinprotein interactions. Previously known and recapitulated protein-protein interactions are shown as lines; arrows pointing from bait to prey denote novel interactions. Double-headed arrows indicate interactions that were recovered as both bait and prey.

\section{Utp25 and Utp3 are not required for SSU processome assembly}

The interactions obtained in our yeast two-hybrid analysis for Utp 25 and Utp3 clearly suggest that both proteins participate in the protein-protein interactions that link the UtpB and Mpp10 subcomplexes of the SSU processome. Both proteins are essential components of the SSU processome, and their genetic depletion results in a loss of prerRNA processing at sites $A_{0}, A_{1}$, and $A_{2}$ (Dragon et al. 2002; this study). Therefore, we asked whether the absence of Utp25 or of Utp3 alters the assembly of the SSU processome from its pre-formed subcomplexes.

We created C-terminal TAP-tagged versions of $t$-Utp8, Utp18, and Rrp9, respective members of the t-Utp/UtpA, UtpB, and U3 snoRNP subcomplexes, in the GAL::3xHAUTP25 and GAL::3xHA-UTP3 strains. We genetically depleted Utp25 or Utp3, coimmunoprecipitated the SSU processome with anti-Mpp10 antibodies, then assayed for the presence of the t-Utp/UtpA, UtpB, and U3 snoRNP subcomplexes by Western analysis with anti-TAP antibodies. Our results suggest that the SSU processome continues to form in the absence of Utp25 or of Utp3, based on the continued presence of $\mathrm{t}-\mathrm{Utp} / \mathrm{Utp} A$, UtpB, or U3 snoRNP protein components in the Mpp10 coimmunoprecipitate (Fig. 8). Therefore, the presence of neither Utp25 nor Utp3 is required for assembly of these subcomplexes into the SSU processome.

\section{DISCUSSION}

We have characterized a new component of the SSU processome, which we have called "Utp25." Previous studies have localized Utp25 to the nucleolus (Hazbun et al. 2003; Huh et al. 2003; Ahmad et al. 2009), the site of ribosome biosynthesis. Furthermore, while this work was in progress, a high-throughput screen using network-guided genetics found UTP25/YIL091C to be involved in ribosomal SSU synthesis (Li et al. 2009). Our study validates and amplifies their findings. We have shown by coimmunoprecipitation studies that Utp25 associates with U3 snoRNA and with Mpp10, both components of the SSU processome. Furthermore, Utp25 is likely associated with the assembled SSU processome as seen by its ability to coimmunoprecipitate members of the t-UtpA, UtpB, Mpp10, and U3 snoRNP subcomplexes. Furthermore, genetic depletion of Utp25 abrogates $18 \mathrm{~S}$ rRNA processing through the loss of cleavage events at sites $A_{0}, A_{1}$, and $A_{2}$ in the $35 S$ pre-rRNA. We also 


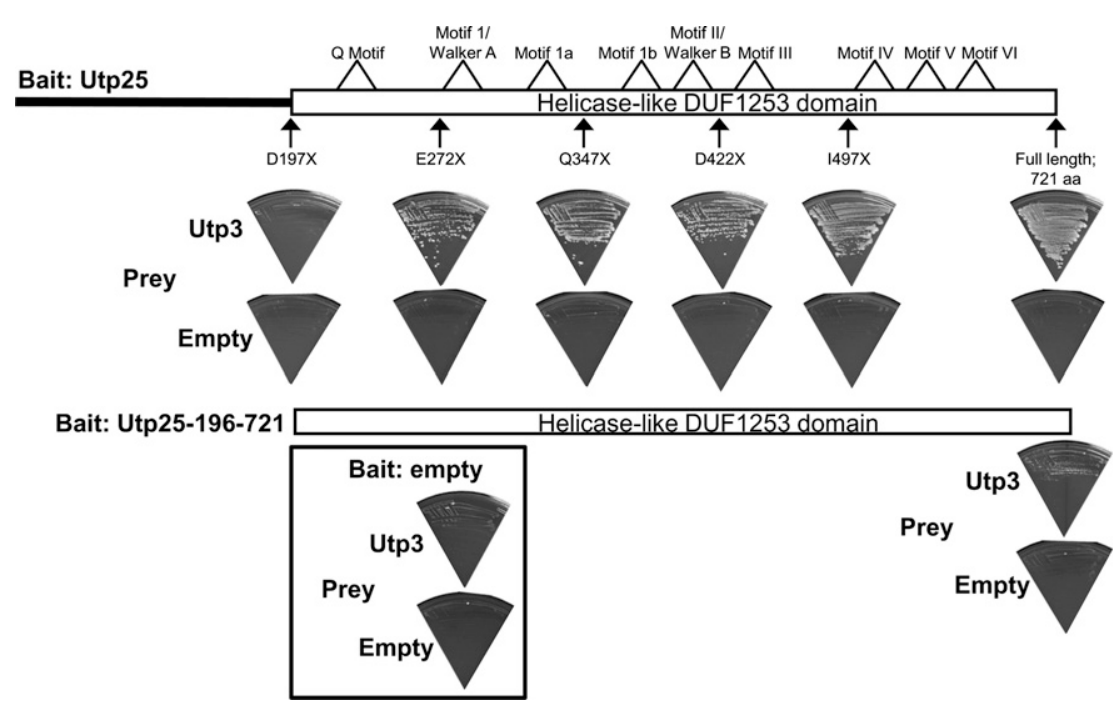

FIGURE 7. The helicase-like domain of Utp25 mediates protein-protein interactions with Utp3. The full-length and N- and C-terminal truncations of Utp25 were cloned as bait, and the full-length Utp3 was cloned as prey, transformed into yeast and screened by yeast two-hybrid in an all-against-all mating array. Yeast cells were assayed for growth on selective medium, as described in the legend to Figure 6. The locations of the C-terminal truncations of Utp25, along with the N-terminal truncation corresponding to the helicase-like DUF1253 motif, are shown. The C-terminal truncations lie outside of the predicted location of the degenerate helicase motifs.

show, using the yeast two-hybrid system, that Utp25 directly interacts with Utp3 and with the Mpp10 and UtpB subcomplexes. Lastly, we find that Utp25 and Utp3 are not required for the assembly of the $t-U t p / U t p A, U t p B$, and Mpp10 subcomplexes of the SSU processome.

A study of essential but uncharacterized yeast open reading frames (Hazbun et al. 2003) annotated UTP25/ YIL091C as a putative DEAD-box RNA helicase. This was based on homology searches (i.e., BLAST) and de novo protein structure predictions that identified DEAD-box RNA-helicase-like sequence and structure elements in Utp25. Our more detailed examination of Utp25 confirms the presence of these helicase elements, namely, motif Ia (Fig. 2; Supplemental Fig. S1). However, elements that carry out enzymatic function, such as the DEAD motif, are clearly absent from Utp25. Furthermore, yeast in which the only helicaselike element in Utp25, motif Ia, has been mutated to alanines display no growth defects. Similarly, mutation of a putative "arginine finger" within the degenerate motif VI sequence results in no phenotypic consequences. Therefore, based on the absence of catalytic sequence elements and on the absence of growth defects upon mutational ablation of motif Ia and of the putative "arginine finger," it is highly unlikely that Utp25 is a bona fide DEAD-box RNA helicase.

The function of motif Ia has been less well studied biochemically, although it is generally accepted that it is involved in RNA binding (Rogers et al. 2002; Rocak and Linder 2004; Cordin et al. 2006). Furthermore, it has been suggested that motif Ia may also be involved in the structural rearrangements that take place during ATP binding and hydrolysis (Schwer and Meszaros 2000; Cordin et al. 2006), a concept substantiated by the discovery of interactions between the first residues of motif Ia (PT) and the glutamate of the DEAD motif (Story et al. 2001; Zhao et al. 2004). In the few studies that have examined motif Ia in bona fide DEAD/ DEAH-box RNA helicases, such as eIF4A (Svitkin et al. 2001), Prp28 (Chang et al. 1997), Prp43 (Tanaka and Schwer 2006), and the Vaccinia virus NPH-II DExHbox helicase (Gross and Shuman 1998), mutation of the motif often abrogated ATP hydrolysis, RNA binding, and RNA helicase activities in vitro, with concomitant lethal, cold-sensitive/temperaturesensitive, and/or dominant-negative phenotypes in vivo. Similarly, in human eIF4AIII, motif Ia is critical for exon junction complex formation and nonsense-mediated mRNA decay (Shibuya et al. 2006). Yet, alanine substitution in motif Ia of the DEAH-box RNA helicase Prp22 resulted in a minor or no effect on yeast growth (Schneider et al. 2004). Indeed, helicases often display variability in their sensitivity to mutation of their conserved motifs (Bernstein et al. 2006; Granneman et al. 2006a), including the DEAD-box itself
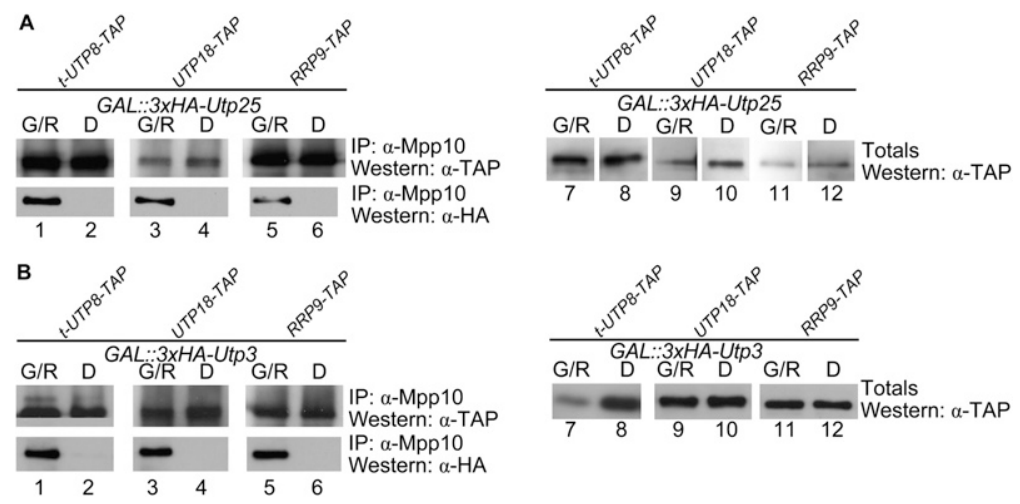

FIGURE 8. Genetic depletion of Utp25 or of Utp3 does not alter SSU processome assembly. Cells were genetically depleted of Utp25 $(A)$ or of Utp3 $(B)$, and the SSU processome was coimmunoprecipitated with anti-Mpp10 antibodies. The presence of TAP-tagged t-Utp8, Utp18, or Rrp9 was assessed by Western analysis with anti-TAP antibodies. Genetic depletion of Utp25 or of Utp3 was confirmed by re-probing the blots with anti-HA antibodies. 
(Shibuya et al. 2006). While motif Ia is dispensable for function in Utp25, this does not mean that it could not also have a contributory role in RNA binding.

The function of the "arginine finger" has been relatively well characterized. Typically, mutation of the "arginine finger," as is seen with Prp16, Prp43, and others, abolishes ATPase and helicase activity and leads to dominant-negative or lethal phenotypes (Hotz and Schwer 1998; Caruthers et al. 2000; Martin et al. 2002; Elles and Uhlenbeck 2008). In the case of Utp25, mutation of the putative "arginine finger" resulted in no discernable phenotypic differences at all temperatures tested. Thus, we propose that this arginine does not serve as an "arginine finger" in Utp25.

If Utp25 is not a helicase, then why does it contain sequence elements reminiscent of DEAD-box RNA helicases? Our extensive database search identified homologs of Utp25 in all eukaryotic supergroups (Supplemental Fig. S1; Keeling et al. 2005), suggesting that this protein was present in the common ancestor of all eukaryotes. Furthermore, alignment of Utp25 with known DEAD-box RNA helicases identifies the conserved motif Ia and portions of motifs $\mathrm{Q}$, IV, and V (Fig. 2; Supplemental Fig. S1). Notably, some sequence similarity is also seen surrounding, but not including, the conserved helicase motifs. Thus, the following evolutionary scenario represents the most parsimonious explanation of the observed sequence features and biochemical data. In the common eukaryotic ancestor, a bona fide DEAD-box RNA helicase underwent a gene duplication event, thereby creating two paralogous copies of the helicase gene. Considering that all DEAD-box RNA helicases share the same conserved sequence motifs and are thus likely paralogs, multiple independent helicase gene duplication events must have occurred (Aubourg et al. 1999; Marchat et al. 2008). Over the course of evolutionary time, selective pressures maintained the helicase function of one copy while the second copy, which became Utp25, underwent progressive sequence divergence and eventual loss of most helicase motifs. In present day, this is seen in the few remaining helicase motifs, namely, Ia and regions of Q, $\mathrm{IV}$, and $\mathrm{V}$ and also in the conserved sequences flanking, but not including, the motifs that carry out enzymatic functions. This scenario may not be unique to Utp25, with other examples of paralogous SSU processome proteins possibly including Utp23 and Utp24 (Bleichert et al. 2006). Therefore, since Utp25 is likely a degenerate DEAD-box RNA helicase, its remnant helicase motifs resulted in it being erroneously annotated as a DEAD-box protein.

The SSU processome is a very large ribonucleoprotein particle, of similar size to the ribosome itself (Dragon et al. 2002). Studies on the assembly and function of other large ribonucleoproteins, such as the spliceosome, have been greatly aided by the use of in vitro assembly systems (Kataoka and Dreyfuss 2004; Behzadnia et al. 2006). In the absence of an in vitro reconstitution system for ribosome biogenesis, our ability to generate an assembly map of the
SSU processome has been limited (Pérez-Fernández et al. 2007). To better understand how individual components of the SSU processome are assembled, we have previously determined interaction maps of the $\mathrm{t}$-Utp/UtpA (Freed and Baserga 2010), UtpB (Champion et al. 2008), and Mpp10 subcomplexes (Lee and Baserga 1999), using a yeast twohybrid approach. While these interaction maps delineate the contacts within a subcomplex, they revealed no connections between the various subcomplexes of the SSU processome. Through our study of the interacting partners of Utp25, we have identified the first protein-protein interactions, involving Utp25 and Utp3, that provide multiple connections between the UtpB and Mpp10 subcomplexes. More specifically, we find that the C-terminal domain of Utp25 is required and sufficient for interaction with Utp3. In addition, Utp6 interacts directly with Mpp10, thereby providing an additional link between the UtpB and Mpp10 subcomplexes. It is precisely these types of inter-subunit interactions that promote the proper spatial and temporal association of the various subunits of the SSU processome during the multiple steps of SSU biogenesis.

The novel interactions obtained in our yeast two-hybrid screen for Utp25 and Utp3 suggest that these proteins form some of the first identified protein-protein interactions linking the UtpB and Mpp10 subcomplexes. We therefore examined whether depletion of Utp25 or of Utp3 perturbs the assembly of the SSU processome. Our results show that t-Utp/UtpA, UtpB, Mpp10, and U3 snoRNP subcomplexes remain stably associated with the SSU processome in the absence of Utp25 or of Utp3. One interpretation is that Utp25 and Utp3 are recruited to the SSU processome after the assembly of the t-Utp/UtpA, UtpB, and U3 snoRNP subcomplexes. In contrast, genetic depletion of t-Utp4, a member of the $t-U t p / U t p A$ subcomplex that is the first assembly component of the SSU processome, abrogates SSU processome assembly (Pérez-Fernández et al. 2007; Freed and Baserga 2010). Alternatively, the redundancy observed in the protein-protein interaction network linking the UtpB and Mpp10 subcomplexes, such as between Utp6 and Mpp10, is sufficient to mitigate the loss of the protein interactions provided by either Utp25 or Utp3.

Utp25 is widely conserved throughout eukaryotes (Supplemental Fig. S1). Interestingly, the function of this protein has previously been studied in zebrafish (Chen et al. 2005; Stuckenholz et al. 2009). In a forward mutation screen, a loss-of-function mutation of the zebrafish homo$\log (27.6 \%$ identical, $52.4 \%$ similar to the yeast Utp25) resulted in homozygous mutant fish displaying formed but severely hypoplastic digestive organs, such as a large, unabsorbed yolk sack and under-expanded intestine, liver, exocrine pancreas, and gallbladder at $5.5 \mathrm{~d}$ post-fertilization (dpf) (Chen et al. 2005). In contrast, organs derived from the ectoderm and mesoderm, including body size, appeared normal in the mutant fish. Thus, the zebrafish homolog of Utp25 was called "digestive-organ expansion factor" (def). 
As would be expected from an essential gene, the mutant fish die between 8 and $11 \mathrm{dpf}$.

An ever growing list of ribosome biogenesis factors is now associated with human disease. Collectively known as "ribosomopathies," these diseases include diverse developmental defects (Armistead et al. 2009), hematological disorders/bone marrow failure syndromes (Dokal and Vulliamy 2008), and cancers (Ruggero and Pandolfi 2003; for review, see Freed et al. 2009). More germane to this study, a related phenotype is seen in another SSU processome protein, Utp4, the human homolog of which is called Cirhin. Mutations in the C-terminal region of Cirhin cause liver failure in children (Chagnon et al. 2002). Thus, mutations in Cirhin and in Utp25/def both result in digestive organ failure. However, as with the developmental and hematological disorders listed above, the phenotypic distribution of the affected tissues is difficult to reconcile since all cells and tissues require constant ribosome biogenesis in order to fulfill the basic protein synthesis needs of all cells.

With Utp25 clearly established as an SSU processome component, future studies can explore the discrepancy in the tissue-specific expression of phenotypic defects seen in Utp25/def mutant fish. These may include the possibilities that Utp25 is preferentially expressed in digestive organ tissues, is alternatively spliced (Chen et al. 2005; Bhasi et al. 2009), possesses tissue-specific interacting protein partners, and/or displays digestive organ-specific functions in ribosome biosynthesis. Considering that all cells need the continuous assembly of new ribosomes for basic gene expression, growth, and development, this may help elucidate the indispensable roles of Utp25/def and Utp4/Cirhin in digestive organ development.

\section{MATERIALS AND METHODS}

\section{Bioinformatics searches and analyses}

Initial searches for novel SSU processome components were performed at the Saccharomyces Genome Database (SGD; http:// www.yeastgenome.org/) (Issel-Tarver et al. 2002). Homologs of the yeast UTP25 were identified by BLAST (Altschul et al. 1990) sequence similarity searches at GenBank (http://www.ncbi.nlm. nih.gov/blast/). Sequence alignments were initially generated using ClustalX (Thompson et al. 1997) and manually edited with BioEdit (Hall 1999).

\section{Yeast strains and media}

Saccharomyces cerevisiae strains were derived from the parental YPH499 (mata ura3-52 lys2-80 ade2-101 trp1- $\Delta 63$ his3- $\Delta 200$ leu2- $\Delta 1$ ) strain, except where indicated. A yeast strain carrying a chromosomally integrated galactose-inducible/glucose-repressible promoter with a triple hemagglutinin ( $3 \mathrm{xHA}$ ) epitope tag at the $\mathrm{N}$ terminus of the protein product of UTP25 was constructed using plasmid pFA6a-kanMX6-PGAL1-3xHA and oligonucleotide primers complementary to UTP25 (all oligonucleotide sequences available upon request) (Longtine et al. 1998). GAL::3xHA-UTP25 strains carrying C-terminal TAP-tag fusion of t-Utp8, Utp18, or Rrp9 were constructed using plasmid pBS1479 and primers complementary to t-Utp8, Utp18, or Rrp9 (Puig et al. 2001). Yeast strains were grown at $30^{\circ} \mathrm{C}$ in YPD $(1 \%$ yeast extract, $2 \%$ peptone, and $2 \%$ glucose), and GAL::3xHA strains were grown in YPG/R (1\% yeast extract, $2 \%$ peptone, $2 \%$ galactose, and $2 \%$ raffinose). The GAL::3xHA strains encoding TAP-tagged proteins were grown in synthetic complete medium lacking tryptophan and supplemented with $2 \%$ dextrose (SD-Trp; Clontech) or with $2 \%$ galactose plus $2 \%$ raffinose (SG/R-Trp; Clontech). Strains harboring p415-GPD, p415-GPD::UTP25, or p415-GPD::utp25-mutant plasmids (LEU2 marker) were grown in SD-Leu or SG/R-Leu (Clontech).

\section{Growth analysis}

Genetic depletion of Utp25 was accomplished by growth of the $G A L:: 3 H A-U T P 25$ strain to mid-log phase $\left(\mathrm{OD}_{600}\right.$ of 0.6 to 0.8$)$ in permissive media (YPG/R). The cells were then washed with water and transferred to nonpermissive media (YPD) for depletion. The cells were maintained in mid-log phase $\left(\mathrm{OD}_{600}<0.8\right)$ by frequent dilution of the culture with fresh YPD media (Bernstein and Baserga 2004). Growth was monitored by $\mathrm{OD}_{600}$ measurement for up to $24 \mathrm{~h}$. Yeast strains YPH499 and GAL::3HA-UTP6 (Dragon et al. 2002) were used as negative and positive controls, respectively. After 0 and $24 \mathrm{~h}$ of depletion, cells were analyzed for expression of the 3xHA-tagged proteins by Western blotting with an $\alpha$-HA mAb (1:500; culture supernatant of mouse monoclonal hybridoma 12CA5). For complementation assays, the GAL::3HAUTP25 strain harboring p415-GPD, p415-GPD::UTP25, or p415GPD::utp25-mutant plasmids was grown to mid-log phase in permissive media (SG/R-Leu). The cells were washed and transferred to nonpermissive media (SD-Leu) for depletion. The cells were maintained in mid-log phase, and growth was monitored by $\mathrm{OD}_{600}$ measurement, all as described above.

\section{Analysis of pre-rRNA processing by Northern hybridization}

Cells were genetically depleted of Utp25 by growth of the GAL::3HA-UTP25 strain in YPD for $0 \mathrm{~h}, 12 \mathrm{~h}$, and $24 \mathrm{~h}$, along with the parental YPH499 and positive control GAL::3HA-UTP6 (Dragon et al. 2002) strains. Total RNA was extracted from 10 OD units of cells at an $\mathrm{OD}_{600}$ of $\sim 0.5$ using the hot acid phenol method, as previously described (Ausubel et al. 1989; Champion et al. 2008). Twenty micrograms of RNA from genetically depleted and undepleted cells was resolved on the same $1.25 \%$ agarose/ formaldehyde gel, transferred to Hybond $\mathrm{N}^{+}$membrane, UV cross-linked, and hybridized (Dunbar et al. 1997). Pre-rRNAs and mature rRNAs were detected by sequential hybridization with $\left[\gamma-{ }^{32} \mathrm{P}\right]$ ATP 5 -end-labeled (Ausubel et al. 1989) oligonucleotides c (detects the $35 \mathrm{~S}, 33 \mathrm{~S}, 32 \mathrm{~S}, 27 \mathrm{SA}_{2}$, and $23 \mathrm{~S}$ pre-rRNAs), b, and e (detects the $20 \mathrm{~S}$ and the $27 \mathrm{SA}_{3}$ and $27 \mathrm{SB}$ pre-rRNAs, respectively), and a and $y$ (detect the mature $18 \mathrm{~S}$ and $25 \mathrm{~S}$ rRNAs, respectively) (Wehner et al. 2002; Bleichert et al. 2006).

\section{Coimmunoprecipitations}

Ten OD units of actively growing cells $\left(\mathrm{OD}_{600}\right.$ of 0.3 to 0.7$)$ were harvested from the parental strain YPH499, from GAL::3HAUTP25 or GAL::3HA-UTP3 and their TAP-tagged derivatives, 
and/or from the positive control strain GAL::3HA-UTP6 (Dragon et al. 2002). When necessary, cells were genetically depleted of Utp 25 or Utp 3 by growth in dextrose for 18 to $20 \mathrm{~h}$. The cells were lysed by glass bead breakage (Champion et al. 2008). Cell extracts were immunoprecipitated with $200 \mu \mathrm{L}$ of $\alpha$-HA mAb coupled to $3 \mathrm{mg}$ of protein A-Sepharose beads (CL-4B; GE Healthcare) (Champion et al. 2008) or with $100 \mu \mathrm{L}$ of $\alpha$-Mpp10 antibodies (rabbit polyclonal) (Dunbar et al. 1997) coupled to $2.5 \mathrm{mg}$ of protein A-Sepharose beads. For the Western blots, the immunoprecipitated proteins and $5 \%$ of the total input were resolved in an SDS-PAGE gel, transferred to a membrane, and blotted with $\alpha$-Mpp10 antibodies (Dunbar et al. 1997), $\alpha$-HA mAb or $\alpha$-TAP $\mathrm{Ab}$, as described below. For the Northern hybridization, RNA was extracted from the total input and immunoprecipitated proteins as previously described (Dunbar et al. 1997). The immunoprecipitated RNA and $10 \%$ of the total input were separated on an $8 \%$ urea-acrylamide gel, transferred to a Hybond $\mathrm{N}^{+}$membrane (Amersham Biosciences), and UV cross-linked (Dunbar et al. 1997). The membrane was hybridized with a $\left[\gamma^{-32} \mathrm{P}\right]$ ATP $5^{\prime}$-endlabeled (Ausubel et al. 1989) oligonucleotide probe complementary to U3 snoRNA.

\section{Western analysis}

Proteins, from yeast whole-cell extract or from coimmunoprecipitations, were resolved on 10\% SDS-PAGE gels and transferred to PVDF membranes (PerkinElmer). Blots were incubated with primary antibodies, $\alpha$-Mpp10 (1:10,000) (Dunbar et al. 1997), $\alpha$-HA mAb (1:500) or $\alpha$-TAP $(0.5: 10,000$; peroxidase antiperoxidase Ab; PAP; Sigma), and the corresponding secondary antibody (anti-rabbit IgG at 1:10,000 [GE Healthcare] or antimouse IgG at 1:10,000 [Amersham Biosciences]) and detected by chemoluminescence (Millipore Immobilon) (Dunbar et al. 1997; Lee and Baserga 1999). When necessary, blots were stripped by $20 \mathrm{~min}$ incubation at $65^{\circ} \mathrm{C}$ in $20 \mathrm{~mL}$ of Western stripping solution and re-probed as described.

\section{Cloning and mutagenesis}

UTP25 was PCR-amplified from yeast total DNA (YPH499) using Herculase DNA polymerase (Stratagene) and oligonucleotide primers that incorporate $\mathrm{NcoI}$ and $\mathrm{XhoI}$ restriction sites into the $5^{\prime}$ - and $3^{\prime}$-ends of the gene. PCR products were cloned into pCR4-TOPO (Invitrogen) and subsequently subcloned into the NcoI and XhoI sites of p415-GPD (a low-copy yeast expression vector with a constitutive GPD promoter; Amp ${ }^{\mathrm{R}}$, LEU2 marker, and CEN/ARS origin of replication) (Mumberg et al. 1995). Mutations were introduced into Utp25 in the p415-GPD vector using oligonucleotide primers and the QuikChange Site-Directed Mutagenesis Kit (Stratagene), according to the manufacturer's protocol. All wild-type and mutant Utp25 sequences were confirmed by sequence analysis.

\section{Yeast two-hybrid screen}

The genes encoding all full-length protein constituents (UtpB: Utp1, Utp6, Utp12, Utp13, Utp18, and Utp21; Utp3, Utp25, Mpp10, Imp3, and Imp4) were obtained from the yeast movable open reading frame (yeast MORF) collection (Gelperin et al. 2005). N- and C-terminal truncations of Utp 25 were created by
PCR amplification of yeast total DNA using primers complementary to the desired region of Utp25. All Utp25 truncations were initially cloned into pDONR221 and confirmed by sequence analysis. Each MORF clone was transferred by in vitro recombination cloning (Hartley et al. 2000) into both pAS-GW-attR (bait, TRP1 marker, pAS2-1 derived) and pACT-GW-attR (prey, LEU2 marker, pACT2 derived) Gateway (Invitrogen) recombinatorial cloning-converted yeast two-hybrid vectors (Nakayama et al. 2002) by the LR reaction and validated by restriction digestion mapping and sequencing. Bait pAS-GW plasmids were transformed by the LiOAc/PEG method (Walhout and Vidal 2001) into the yeast strain PJ69-4 $\alpha$ and prey pACT-GW plasmids into the PJ69-4a strain, which contains a HIS3 reporter gene under the control of the GAL4 promoter (James et al. 1996), and plated or pinned on the appropriate selection medium (SD-Trp or SD-Leu, respectively). Autoactivating bait clones were identified by growth on SC-Trp-His media with $3 \mathrm{mM}$ 3-aminotriazole (3-AT) (Walhout and Vidal 2001). Yeast cells were mated (Bendixen et al. 1994; Cagney et al. 2000) in an 11-by-11 array of all pairwise combinations on 2 XYPDA media ( $2 \%$ yeast extract, $4 \%$ peptone, $4 \%$ glucose, and $80 \mathrm{mg} / \mathrm{L}$ adenine hemisulfate) (Gietz and Schiestl 2007) and pinned onto SD-Leu-Trp medium for selection of diploid cells. Diploids were then pinned or struck-out onto selective medium (SC-Leu-Trp-His) with $3 \mathrm{mM} 3$-AT and scored for growth. Interactions involving the auto-activating Utp3 and Utp18 (Champion et al. 2008) bait fusion proteins were examined on $15 \mathrm{mM} 3$-AT. The yeast two-hybrid experiment was replicated three times.

\section{SUPPLEMENTAL MATERIAL}

Supplemental material can be found at http://www.rnajournal.org.

\section{ACKNOWLEDGMENTS}

We thank Stacy Piccirillo and Daniel M. Gelperin of Michael Snyder's laboratory for technical advice with recombinatorial cloning and for kindly providing us with MORF library clones. In addition, we are thankful to Dr. Shusei Sato (Kazusa DNA Research Institute, Japan), for the Gateway converted yeast twohybrid vectors and Dr. Stanley Fields (University of Washington) for the yeast two-hybrid yeast strains. We are grateful to all members of the Baserga Laboratory and to Dr. Ellen Boudreau for advice, discussion, technical assistance, and for critical reading of the manuscript. This work was supported by NIH GM 52581 (to S.J.B.) and NIH T32 CA009259 Post-Doctoral NIH-Ruth L. Kirschstein National Research Service Award, Institutional Research Training Grant: Radiation Therapy, Biology, Physics (to J.M.C.).

Received November 4, 2009; accepted August 5, 2010.

\section{REFERENCES}

Ahmad Y, Boisvert FM, Gregor P, Cobley A, Lamond AI. 2009. NOPdb: Nucleolar Proteome Database-2008 update. Nucleic Acids Res 37: D181-D184.

Altschul SF, Gish W, Miller W, Myers EW, Lipman DJ. 1990. Basic local alignment search tool. J Mol Biol 215: 403-410. 
Armistead J, Khatkar S, Meyer B, Mark BL, Patel N, Coghlan G, Lamont RE, Liu S, Wiechert J, Cattini PA, et al. 2009. Mutation of a gene essential for ribosome biogenesis, EMG1, causes BowenConradi syndrome. Am J Hum Genet 84: 728-739.

Ashburner M, Ball CA, Blake JA, Botstein D, Butler H, Cherry JM, Davis AP, Dolinski K, Dwight SS, Eppig JT, et al. 2000. Gene Ontology: Tool for the unification of biology. The Gene Ontology Consortium. Nat Genet 25: 25-29.

Aubourg S, Kreis M, Lecharny A. 1999. The DEAD box RNA helicase family in Arabidopsis thaliana. Nucleic Acids Res 27: 628-636.

Ausubel FM, Brent R, Kingston RE, Moore DD, Seidman JG, Smith JA, Struhl K. 1989. Current protocols in molecular biology. Wiley, Toronto.

Behzadnia N, Hartmuth K, Will CL, Lührmann R. 2006. Functional spliceosomal A complexes can be assembled in vitro in the absence of a penta-snRNP. RNA 12: 1738-1746.

Beltrame M, Tollervey D. 1995. Base pairing between U3 and the pre-ribosomal RNA is required for $18 \mathrm{~S}$ rRNA synthesis. $E M B O$ J 14: 4350-4356.

Bendixen C, Gangloff S, Rothstein R. 1994. A yeast mating-selection scheme for detection of protein-protein interactions. Nucleic Acids Res 22: 1778-1779.

Bernstein KA, Baserga SJ. 2004. The small subunit processome is required for cell cycle progression at $\mathrm{G}_{1}$. Mol Biol Cell 15: 50385046.

Bernstein KA, Gallagher JE, Mitchell BM, Granneman S, Baserga SJ. 2004. The small-subunit processome is a ribosome assembly intermediate. Eukaryot Cell 3: 1619-1626.

Bernstein KA, Granneman S, Lee AV, Manickam S, Baserga SJ. 2006. Comprehensive mutational analysis of yeast DEXD/H box RNA helicases involved in large ribosomal subunit biogenesis. Mol Cell Biol 26: 1195-1208.

Bhasi A, Philip P, Sreedharan VT, Senapathy P. 2009. AspAlt: A tool for inter-database, inter-genomic and user-specific comparative analysis of alternative transcription and alternative splicing in 46 eukaryotes. Genomics 94: 48-54.

Bleichert F, Baserga SJ. 2007. The long unwinding road of RNA helicases. Mol Cell 27: 339-352.

Bleichert F, Granneman S, Osheim YN, Beyer AL, Baserga SJ. 2006. The PINc domain protein Utp24, a putative nuclease, is required for the early cleavage steps in $18 \mathrm{~S}$ rRNA maturation. Proc Natl Acad Sci 103: 9464-9469.

Cagney G, Uetz P, Fields S. 2000. High-throughput screening for protein-protein interactions using two-hybrid assay. Methods Enzymol 328: 3-14.

Caruthers JM, Johnson ER, McKay DB. 2000. Crystal structure of yeast initiation factor 4A, a DEAD-box RNA helicase. Proc Natl Acad Sci 97: 13080-13085.

Chagnon P, Michaud J, Mitchell G, Mercier J, Marion JF, Drouin E, Rasquin-Weber A, Hudson TJ, Richter A. 2002. A missense mutation (R565W) in Cirhin (FLJ14728) in North American Indian childhood cirrhosis. Am J Hum Genet 71: 1443-1449.

Champion EA, Lane BH, Jackrel ME, Regan L, Baserga SJ. 2008. A direct interaction between the Utp6 half-a-tetratricopeptide repeat domain and a specific peptide in Utp21 is essential for efficient pre-rRNA processing. Mol Cell Biol 28: 6547-6556.

Chang TH, Latus LJ, Liu Z, Abbott JM. 1997. Genetic interactions of conserved regions in the DEAD-box protein Prp28p. Nucleic Acids Res 25: 5033-5040.

Chen J, Ruan H, Ng SM, Gao C, Soo HM, Wu W, Zhang Z, Wen Z, Lane DP, Peng J. 2005. Loss of function of def selectively upregulates Delta113p53 expression to arrest expansion growth of digestive organs in zebrafish. Genes Dev 19: 2900-2911.

Cordin O, Banroques J, Tanner NK, Linder P. 2006. The DEAD-box protein family of RNA helicases. Gene 367: 17-37.

Dokal I, Vulliamy T. 2008. Inherited aplastic anaemias/bone marrow failure syndromes. Blood Rev 22: 141-153.

Dragon F, Gallagher JE, Compagnone-Post PA, Mitchell BM, Porwancher KA, Wehner KA, Wormsley S, Settlage RE, Shabanowitz J, Osheim Y, et al. 2002. A large nucleolar U3 ribonucleoprotein required for $18 \mathrm{~S}$ ribosomal RNA biogenesis. Nature 417: 967-970.

Dunbar DA, Wormsley S, Agentis TM, Baserga SJ. 1997. Mpp10p, a U3 small nucleolar ribonucleoprotein component required for pre-18S rRNA processing in yeast. Mol Cell Biol 17: 5803-5812.

Elles LM, Uhlenbeck OC. 2008. Mutation of the arginine finger in the active site of Escherichia coli DbpA abolishes ATPase and helicase activity and confers a dominant slow growth phenotype. Nucleic Acids Res 36: 41-50.

Freed EF, Baserga SJ. 2010. The C-terminus of Utp4, mutated in childhood cirrhosis, is essential for ribosome biogenesis. Nucleic Acids Res 38: 4798-4806.

Freed EF, Bleichert F, Dutca LM, Baserga SJ. 2009. When ribosomes go bad: Diseases of ribosome biogenesis. Mol Biosyst 6: 481-493.

Gallagher JE, Dunbar DA, Granneman S, Mitchell BM, Osheim Y, Beyer AL, Baserga SJ. 2004. RNA polymerase I transcription and pre-rRNA processing are linked by specific SSU processome components. Genes Dev 18: 2506-2517.

Gelperin DM, White MA, Wilkinson ML, Kon Y, Kung LA, Wise KJ, Lopez-Hoyo N, Jiang L, Piccirillo S, Yu H, et al. 2005. Biochemical and genetic analysis of the yeast proteome with a movable ORF collection. Genes Dev 19: 2816-2826.

Giaever G, Chu AM, Ni L, Connelly C, Riles L, Veronneau S, Dow S, Lucau-Danila A, Anderson K, Andre B, et al. 2002. Functional profiling of the Saccharomyces cerevisiae genome. Nature 418: 387391.

Gietz RD, Schiestl RH. 2007. Large-scale high-efficiency yeast transformation using the LiAc/SS carrier DNA/PEG method. Nat Protoc 2: $38-41$.

Goldenberg DP. 1988. Genetic studies of protein stability and mechanisms of folding. Annu Rev Biophys Biophys Chem 17: 481-507.

Granneman S, Baserga SJ. 2005. Crosstalk in gene expression: Coupling and co-regulation of rDNA transcription, pre-ribosome assembly and pre-rRNA processing. Curr Opin Cell Biol 17: 281286.

Granneman S, Bernstein KA, Bleichert F, Baserga SJ. 2006a. Comprehensive mutational analysis of yeast $\mathrm{DEXD} / \mathrm{H}$ box RNA helicases required for small ribosomal subunit synthesis. Mol Cell Biol 26: 1183-1194.

Granneman S, Lin C, Champion EA, Nandineni MR, Zorca C, Baserga SJ. 2006b. The nucleolar protein Esf2 interacts directly with the $\mathrm{DExD} / \mathrm{H}$ box RNA helicase, Dbp8, to stimulate ATP hydrolysis. Nucleic Acids Res 34: 3189-3199.

Gross CH, Shuman S. 1998. The nucleoside triphosphatase and helicase activities of vaccinia virus NPH-II are essential for virus replication. J Virol 72: 4729-4736.

Guthrie C, Nashimoto H, Nomura M. 1969. Structure and function of E. coli ribosomes. 8. Cold-sensitive mutants defective in ribosome assembly. Proc Natl Acad Sci 63: 384-391.

Hall TA. 1999. BioEdit: A user-friendly biological sequence alignment editor and analysis program for Windows 95/98/NT. Nucleic Acids Symp Ser 41: 95-98.

Hartley JL, Temple GF, Brasch MA. 2000. DNA cloning using in vitro site-specific recombination. Genome Res 10: 1788-1795.

Hazbun TR, Malmstrom L, Anderson S, Graczyk BJ, Fox B, Riffle M, Sundin BA, Aranda JD, McDonald WH, Chiu CH, et al. 2003. Assigning function to yeast proteins by integration of technologies. Mol Cell 12: 1353-1365.

Henras AK, Soudet J, Gérus M, Lebaron S, Caizergues-Ferrer M, Mougin A, Henry Y. 2008. The post-transcriptional steps of eukaryotic ribosome biogenesis. Cell Mol Life Sci 65: 2334-2359.

Hotz HR, Schwer B. 1998. Mutational analysis of the yeast DEAH-box splicing factor Prp16. Genetics 149: 807-815.

Hughes JM. 1996. Functional base-pairing interaction between highly conserved elements of U3 small nucleolar RNA and the small ribosomal subunit RNA. J Mol Biol 259: 645-654.

Huh WK, Falvo JV, Gerke LC, Carroll AS, Howson RW, Weissman JS, O'Shea EK. 2003. Global analysis of protein localization in budding yeast. Nature 425: 686-691. 
Issel-Tarver L, Christie KR, Dolinski K, Andrada R, Balakrishnan R, Ball CA, Binkley G, Dong S, Dwight SS, Fisk DG, et al. 2002. Saccharomyces Genome Database. Methods Enzymol 350: 329346.

James P, Halladay J, Craig EA. 1996. Genomic libraries and a host strain designed for highly efficient two-hybrid selection in yeast. Genetics 144: 1425-1436.

Kataoka N, Dreyfuss G. 2004. A simple whole cell lysate system for in vitro splicing reveals a stepwise assembly of the exon-exon junction complex. J Biol Chem 279: 7009-7013.

Keeling PJ, Burger G, Durnford DG, Lang BF, Lee RW, Pearlman RE, Roger AJ, Gray MW. 2005. The tree of eukaryotes. Trends Ecol Evol 20: 670-676.

Krogan NJ, Peng WT, Cagney G, Robinson MD, Haw R, Zhong G, Guo X, Zhang X, Canadien V, Richards DP, et al. 2004. Highdefinition macromolecular composition of yeast RNA-processing complexes. Mol Cell 13: 225-239.

Krogan NJ, Cagney G, Yu H, Zhong G, Guo X, Ignatchenko A, Li J, Pu S, Datta N, Tikuisis AP, et al. 2006. Global landscape of protein complexes in the yeast Saccharomyces cerevisiae. Nature 440: 637643.

Lee SJ, Baserga SJ. 1999. Imp3p and Imp4p, two specific components of the U3 small nucleolar ribonucleoprotein that are essential for pre-18S rRNA processing. Mol Cell Biol 19: 5441-5452.

Li Z, Lee I, Moradi E, Hung NJ, Johnson AW, Marcotte EM. 2009. Rational extension of the ribosome biogenesis pathway using network-guided genetics. PLoS Biol 7: e1000213. doi: 10.1371/ journal.pbio. 1000213.

Longtine MS, McKenzie AR, Demarini DJ, Shah NG, Wach A, Brachat A, Philippsen P, Pringle JR. 1998. Additional modules for versatile and economical PCR-based gene deletion and modification in Saccharomyces cerevisiae. Yeast 14: 953-961.

Marchat LA, Orozco E, Guillen N, Weber C, López-Camarillo C. 2008. Putative DEAD and DExH-box RNA helicases families in Entamoeba histolytica. Gene 424: 1-10.

Martin A, Schneider S, Schwer B. 2002. Prp43 is an essential RNAdependent ATPase required for release of lariat-intron from the spliceosome. J Biol Chem 277: 17743-17750.

Méreau A, Fournier R, Grégoire A, Mougin A, Fabrizio P, Lührmann $\mathrm{R}$, Branlant C. 1997. An in vivo and in vitro structure-function analysis of the Saccharomyces cerevisiae U3A snoRNP: ProteinRNA contacts and base-pair interaction with the pre-ribosomal RNA. J Mol Biol 273: 552-571.

Mumberg D, Muller R, Funk M. 1995. Yeast vectors for the controlled expression of heterologous proteins in different genetic backgrounds. Gene 156: 119-122.

Nakayama M, Kikuno R, Ohara O. 2002. Protein-protein interactions between large proteins: Two-hybrid screening using a functionally classified library composed of long cDNAs. Genome Res 12: 17731784.

Osheim YN, French SL, Keck KM, Champion EA, Spasov K, Dragon F, Baserga SJ, Beyer AL. 2004. Pre-18S ribosomal RNA is structurally compacted into the SSU processome prior to being cleaved from nascent transcripts in Saccharomyces cerevisiae. Mol Cell 16: 943-954.

Peña-Castillo L, Hughes TR. 2007. Why are there still over 1000 uncharacterized yeast genes? Genetics 176: 7-14.

Pérez-Fernández J, Román A, De Las Rivas J, Bustelo XR, Dosil M. 2007. The $90 \mathrm{~S}$ preribosome is a multimodular structure that is assembled through a hierarchical mechanism. Mol Cell Biol 27: 5414-5429.

Puig O, Caspary F, Rigaut G, Rutz B, Bouveret E, Bragado-Nilsson E, Wilm M, Séraphin B. 2001. The tandem affinity purification (TAP) method: A general procedure of protein complex purification. Methods 24: 218-229.

Rocak S, Linder P. 2004. DEAD-box proteins: The driving forces behind RNA metabolism. Nat Rev Mol Cell Biol 5: 232-241.

Rogers GW Jr, Komar AA, Merrick WC. 2002. eIF4A: The godfather of the DEAD box helicases. Prog Nucleic Acid Res Mol Biol 72: 307331.

Ruggero D, Pandolfi PP. 2003. Does the ribosome translate cancer? Nat Rev Cancer 3: 179-192.

Schneider S, Campodonico E, Schwer B. 2004. Motifs IV and V in the DEAH box splicing factor Prp22 are important for RNA unwinding, and helicase-defective Prp22 mutants are suppressed by Prp8. J Biol Chem 279: 8617-8626.

Schwer B, Meszaros T. 2000. RNA helicase dynamics in pre-mRNA splicing. EMBO J 19: 6582-6591.

Sharma K, Tollervey D. 1999. Base pairing between U3 small nucleolar RNA and the $5^{\prime}$ end of $18 \mathrm{~S}$ rRNA is required for pre-rRNA processing. Mol Cell Biol 19: 6012-6019.

Shibuya T, Tange TO, Stroupe ME, Moore MJ. 2006. Mutational analysis of human eIF4AIII identifies regions necessary for exon junction complex formation and nonsense-mediated mRNA decay. RNA 12: $360-374$.

Story RM, Li H, Abelson JN. 2001. Crystal structure of a DEAD box protein from the hyperthermophile Methanococcus jannaschii. Proc Natl Acad Sci 98: 1465-1470.

Strunk BS, Karbstein K. 2009. Powering through ribosome assembly. RNA 15: 2083-2104.

Stuckenholz C, Lu L, Thakur P, Kaminski N, Bahary N. 2009. FACSassisted microarray profiling implicates novel genes and pathways in zebrafish gastrointestinal tract development. Gastroenterology 137: 1321-1332.

Svitkin YV, Pause A, Haghighat A, Pyronnet S, Witherell G, Belsham GJ, Sonenberg N. 2001. The requirement for eukaryotic initiation factor $4 \mathrm{~A}(\mathrm{elF} 4 \mathrm{~A})$ in translation is in direct proportion to the degree of mRNA 5' secondary structure. RNA 7: 382-394.

Tanaka N, Schwer B. 2006. Mutations in PRP43 that uncouple RNAdependent NTPase activity and pre-mRNA splicing function. Biochemistry 45: 6510-6521.

Tarassov K, Messier V, Landry CR, Radinovic S, Molina MM, Shames I, Malitskaya Y, Vogel J, Bussey H, Michnick SW. 2008. An in vivo map of the yeast protein interactome. Science 320: 1465-1470.

Thompson JD, Gibson TJ, Plewniak F, Jeanmougin F, Higgins DG. 1997. The CLUSTAL X windows interface: Flexible strategies for multiple sequence alignment aided by quality analysis tools. Nucleic Acids Res 25: 4876-4882.

Venema J, Tollervey D. 1999. Ribosome synthesis in Saccharomyces cerevisiae. Annu Rev Genet 33: 261-311.

Walhout AJ, Vidal M. 2001. High-throughput yeast two-hybrid assays for large-scale protein interaction mapping. Methods 24: 297-306.

Wehner KA, Gallagher JE, Baserga SJ. 2002. Components of an interdependent unit within the SSU processome regulate and mediate its activity. Mol Cell Biol 22: 7258-7267.

Zhao R, Shen J, Green MR, MacMorris M, Blumenthal T. 2004. Crystal structure of UAP56, a $\mathrm{DExD} / \mathrm{H}$-box protein involved in pre-mRNA splicing and mRNA export. Structure 12: 1373-1381. 

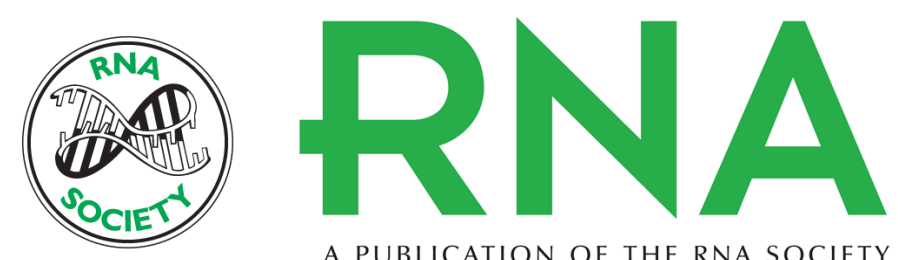

A PUBLICATION OF THE RNA SOCIETY

\section{The DEAD-box RNA helicase-like Utp25 is an SSU processome component}

J. Michael Charette and Susan J. Baserga

RNA 2010 16: 2156-2169 originally published online September 30, 2010

Access the most recent version at doi:10.1261/rna.2359810

\section{Supplemental http://rnajournal.cshlp.org/content/suppl/2010/09/14/rna.2359810.DC1 \\ Material}

References This article cites 80 articles, 29 of which can be accessed free at:

http://rnajournal.cshlp.org/content/16/11/2156.full.html\#ref-list-1

\section{License}

Email Alerting Receive free email alerts when new articles cite this article - sign up in the box at the Service top right corner of the article or click here. 